\title{
Postprandial lipemia and cardiovascular diseases: the beneficial role of strength exercise
}

\author{
Lipemia pós-prandial e doenças cardiovasculares: o papel \\ benéfico dos exercícios de força \\ Cleiton Silva Correa ${ }^{1,2}$, Bruno Costa Teixeira', Aline Bittencourt ${ }^{1}$, \\ Rodrigo Cauduro Oliveira Macedo', Álvaro Reischak-Oliveira'
}

\begin{abstract}
Development of cardiovascular diseases (CVD) has been linked with changes to the lipid profile that can be observed during the postprandial period, a phenomenon known as postprandial lipemia (PL). Physical exercise is currently the number one non-pharmacological intervention employed for prevention and reduction of risk factors for the development of CVD. This in turn has created a growing interest in the effects of physical exercise on regulation and equilibrium of lipid metabolism. In this review we compare the results of studies that have investigated the beneficial effects of strength training on PL. We analyzed articles identified in the PubMed, Scopus and EBSCO databases published from 1975 to 2013 in international journals. Studies were selected for review if they covered at least two of four keywords. The results of these studies lead to the conclusion that strength training is effective for reduction of postprandial lipemia because it increases baseline energy expenditure. This type of training can be prescribed as an important element in strategies to treat chronic diseases, such as atherosclerosis.
\end{abstract}

Keywords: strength training; lipoproteins; atherosclerotic plaques; lipoprotein lipase.

\section{Resumo}

O desenvolvimento de doenças cardiovasculares (DCV) tem sido associado a alterações no perfil lipídico encontradas no período pós-prandial, fenômeno conhecido como lipemia pós-prandial (PL). O exercício fisico é atualmente a principal intervenção não farmacológica utilizada na prevenção e na redução de fatores de risco para o desenvolvimento de DCV. Por esta razão, há um interesse crescente acerca dos efeitos do exercício físico sobre a regulação e o equilíbrio do metabolismo lipídico. Nesta revisão, procuramos comparar os resultados de artigos que abordaram os efeitos benéficos do treinamento de força sobre a PL. Utilizamos artigos que foram selecionados nas bases de dados PubMed, Scopus e EBSCO, no período entre os anos 1975 e 2013, e publicados em revistas internacionais. Os estudos selecionados foram aqueles que contemplassem pelo menos duas das quatro palavras-chave do estudo. Com base nos estudos selecionados, conclui-se que o treinamento de força revela-se eficaz na redução da lipemia pós-prandial por induzir uma melhoria da demanda de energia basal. Este tipo de treinamento pode ser indicado como uma estratégia importante para o tratamento de doenças crônicas, como a aterosclerose.

Palavras-chave: treinamento de força; lipoproteínas; placa aterosclerótica; lipase lipoproteica.

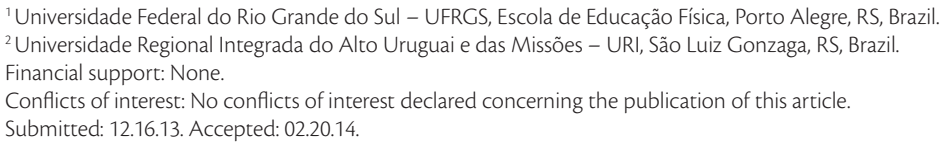

The study was carried out at Universidade Federal do Rio Grande do Sul and Universidade Regional Integrada do Alto Uruguai e das Missões da cidade de São Luiz Gonzaga. 


\section{INTRODUCTION}

Changes to the lipid profile that represent a risk factor for development of cardiovascular diseases (CVD) are commonly observed during atherosclerotic plaque formation and the subsequent inflammatory response. ${ }^{1,2}$ Postprandial lipemia (PL) is a phenomenon that is known to induce endothelial dysfunction by increasing the availability of free fatty acids (FFA) and is often seen in sedentary or overweight individuals. A high $\beta$-oxidation rate induces accumulation of electrons followed by an increase in free radical production (e.g. superoxide radicals), which deviates the course of nitric oxide (NO) utilization, decreasing availability of this potent vasodilator and mediator of defense against atherosclerosis. Endothelial function deteriorates in the same proportion as lipemia increases, as in an acute response to systemic changes, whether chronic or postprandial. ${ }^{3}$

The phenomenon is associated with increased secretion of pro-inflammatory cytokines, expression of adhesion molecules (ICAM, VCAM-1) and prooxidative activity. The endothelial damage observed during this process promotes recruitment of injury-responsive cells by stimulating infiltration of monocytes to the subendothelial space, which differentiate into macrophages (foam cells), which are well-known to exhibit the ability to accumulate large amounts of lipids originating from cytoplasm-generating products that induce tissue damage and reactive oxygen and nitrogen species. Hypertriglyceridemia is a therefore a factor that can stimulate atherogenic potential. ${ }^{4}$

Some studies have reported evidence supporting an important role for regular aerobic exercise in reduction of PL and prevention and control of CVD. ${ }^{3,5-7}$ This has led to growing interest in research into the effects of exercise on lipid metabolism. ${ }^{2}$ Notwithstanding, little is yet known about the preventative effects of strength exercises on development of CVD, through changes in important risk factors such as PL. Strength training apparently reduces total cholesterol concentrations in adults. ${ }^{8}$ However, strength exercise is still used as an additional alternative to aerobic training. ${ }^{9}$

It is believed that, in common with aerobic exercise, strength exercise can help to reduce PL in response to increased lipoprotein lipase (LPL) activity (which is, for example, a key enzyme in triglyceride hydrolysis). ${ }^{10}$ Strength training also increases insulin sensitivity, ${ }^{6}$ reduces plasma concentrations of fasting triglycerides (TAG) and markedly increases baseline fat oxidation for up to
24 hours after a single bout of strength exercise. ${ }^{6}$ This mobilization and utilization of body fat can be particularly useful for reducing PL. ${ }^{1}$

The purpose of this review was therefore to compare results in the literature on the effects of strength exercises on plasma lipoproteins in the postprandial period and their relationship with risk of cardiovascular disease.

\section{METHODS}

This article is based on a review of current references on the subject identified in PubMed, Scopus and EBSCO databases and published in international journals between 1975 and 2013 . The database searches employed terms such as, strength training, resistance training, postprandial lipemia, cardiovascular diseases, volume and intensity. Articles were selected for the review if they addressed a combination of at least two of the four keywords of interest: strength training, lipoproteins, atherosclerotic plaque or lipoprotein lipase activity.

\section{FORMATION, FUNCTION AND USE OF LIPOPROTEINS}

Several important functions have been attributed to lipoproteins, including dissolving and transporting lipids, which are generally hydrophobic substances, from aqueous plasma. The main target lipids are the fatty acids, cholesterol and triglycerides (TAG). Triglycerides are the body's most important form of energy storage, are deposited in adipose and muscle tissues and consist of three fatty acids and one glycerol molecule. ${ }^{12}$ Cholesterol is a member of the group of fats that are essential for life, since it is used in the production of hormones, bile acids and cell membranes. Only $30 \%$ of the cholesterol present in the body comes from the diet, the remainder is synthesized and may be accumulated in arterial walls when in excess. ${ }^{13}$ Hypercholesterolemia may be secondary to dietary or genetic causes, and in most cases is the result of an unbalanced diet rich in saturated fats and a lack of physical activity.

Blood cholesterol is transported by lipoproteins. Several types of lipoproteins are known and these can be grouped into two sets: (a) TAG-rich, larger and less dense lipoproteins, represented by chylomicrons of intestinal origin (responsible for transporting lipids absorbed by the intestine from the diet and enterohepatic circulation), and very low density lipoproteins (VLDL) of hepatic origin; and (b) cholesterol-rich low density lipoproteins (LDL) and high density lipoproteins (HDL). There are also a class of intermediate density lipoproteins (IDL) and 
lipoprotein (a) [Lp (a)], which is the result of covalent bonding of LDL particles to apo (a). ${ }^{10,13}$

From the four classes of lipoproteins listed above, those that are most often assayed in order to test for dyslipidemias and determine whether there is a

Table 1. Reference values for diagnosis of dyslipidemia in adults over the age of 20 (adapted from Pearson et al. ${ }^{15}$ ).

\begin{tabular}{lcc}
\hline Lipids & Values & Level \\
\hline Total Cholesterol (TC) & $<200$ & Ideal \\
& $200-239$ & Borderline \\
& $\geq 240$ & High \\
LDL-cholesterol (LDL-c) & $<100$ & Ideal \\
& $100-129$ & Desirable \\
& $130-159$ & Borderline \\
& $\geq 190$ & Very High \\
HDL-cholesterol (HDL-c) & $<40$ & Low \\
& $>60$ & High \\
Triglycerides (TAG) & $<150$ & Ideal \\
& $150-200$ & Borderline \\
& $201-499$ & High \\
& $\geq 500$ & Very High \\
\hline
\end{tabular}

propensity to CVD are total cholesterol (TC), TAG, HDL cholesterol (HDL-c) and LDL cholesterol (LDL-c). ${ }^{14}$ Reference values for diagnosing dyslipidemias in adults over the age of 20 are shown in Table $1 .{ }^{15}$

Figure 1 illustrates the mechanisms of blood TAG clearance, after strength training, and the sources supplying fatty acids. In the fasting state, after strength training, most of the fatty acids used to synthesize VLDL-TAG are derived from nonesterified fatty acids (NEFA) in the blood which originate from adipose tissue (1). Some fatty acids can also be derived from hepatic TAG droplets, although the relative contribution of this source is still unknown (2). In the fed state, VLDL synthesis is temporarily inhibited (about 1 hour) by the action of insulin. Release of NEFA could contribute to release of fatty acids in the postprandial state, but concentrations are low during the postprandial period due to the antilipolytic effect of insulin in adipose tissues (3). Finally, lipid remnants of chylomicron could provide large amounts of fatty acids to the

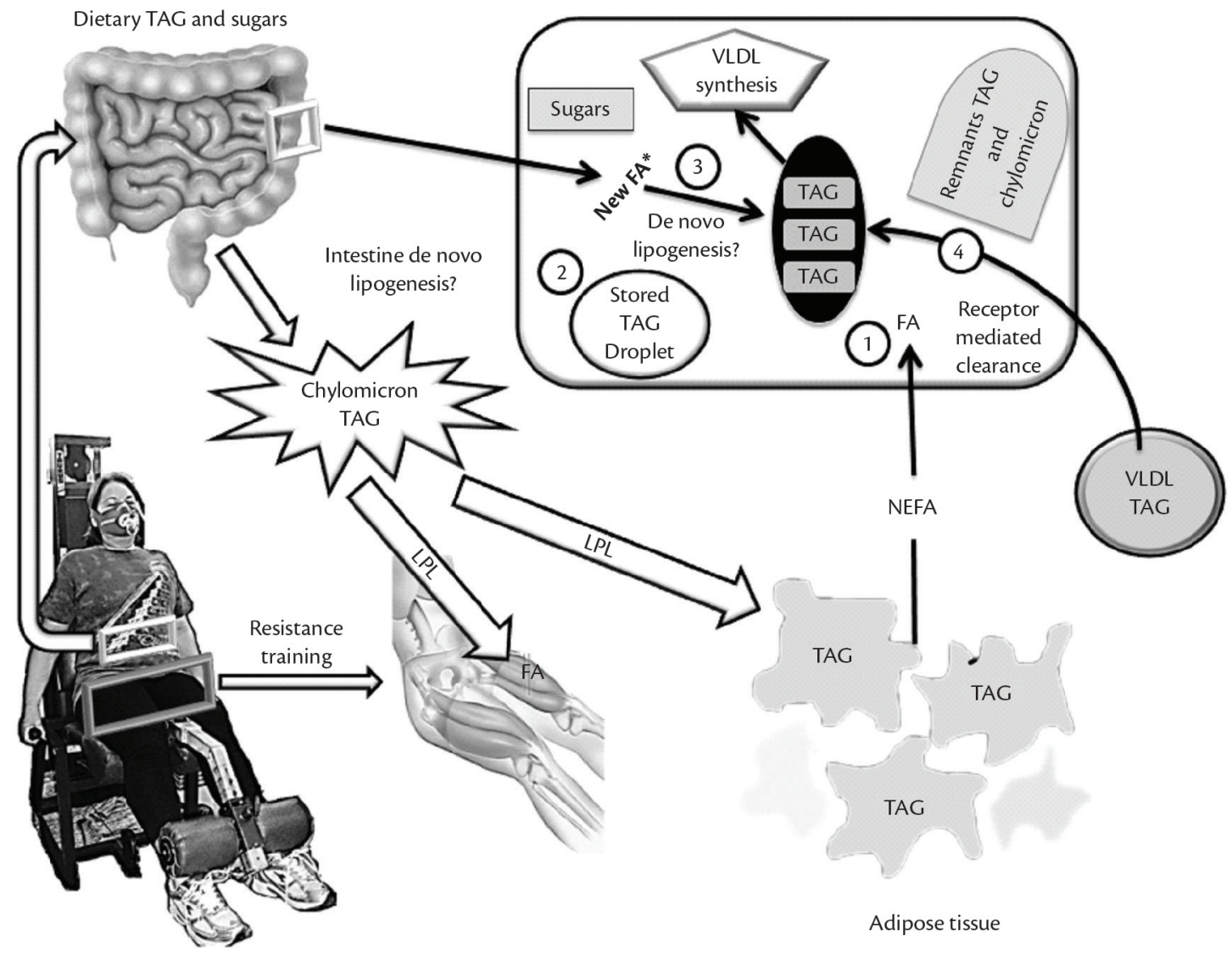

Figure 1. Origin of triglycerides (TG) from exogenous and endogenous lipoproteins and the release mechanisms of triglyceriderich lipoproteins in plasma, baseline state and after strength training. (FA-fatty acid, LPL-lipoprotein lipase; NEFA-non-esterified fatty acids, VLDL-very low density lipoprotein). 
liver, which could be esterified once more to VLDL and then secreted. The contribution of this source of VLDL-TAG has not yet been measured in humans (4). The same is true of de novo intestinal lipogenesis, supplying new fatty acids that become available for chylomicron and TAG production, but this process has not yet been measured. ${ }^{10}$

In the scientific literature, understanding the two mechanisms of TAG release is of paramount importance. The first is mediated by breakdown of fatty acids and their removal from TAGs and the particle-rich lipoproteins that circulate in the blood. Blood TAG reduction has been observed to be proportional to LPL activity. ${ }^{13}$ The second method of clearance of plasma TAG takes place when a triacylglycerol particle is absorbed in the liver by its receptor. ${ }^{13}$

When consumed in excess, TAG tends to deposit on the walls of arteries and form fat plaques (atheroma), which can impair blood flow, stimulate clot production and contribute to narrowing of blood vessels, especially if plasma HDL-c is at low concentrations. ${ }^{16}$

\section{POSTPRANDIAL LIPEMIA AS A RISK FACTOR FOR DEVELOPMENT OF CVD}

Postprandial lipemia can be defined as increased lipoprotein and chylomicron in acute response to a high-lipids meal which then return to baseline levels over time. This methodology has allowed us to trace a relationship between the effect of lipids meals and CVD in normal-weight individuals of both sexes. Measurements of FFA such as NEFA and TAG are often used to reflect PL, since TAG increases in a rapid and significant manner in response to food intake. ${ }^{2}$ Postprandial lipemia measurement opens a new perspective for studies that aim to compare intervention methodologies for treatment and prevention of the deleterious effects of dyslipidemia. ${ }^{17}$

Zilversmit, ${ }^{1}$ proposed that atherogenesis is closely associated with the phenomenon of postprandial hyperlipemia, since experiments with animals and humans have shown that endothelial cells can pick up chylomicron remnants and LDL-c. Clinical studies have shown that the magnitude of postprandial lipemia or even elevated levels of postprandial TAG can predict symptomatic or asymptomatic atherosclerosis, independently of fasting analysis.

Epidemiologic studies, clinical trials and current scientific literature show that increasing PL is directly linked to the progression of atherosclerotic plaques, either through deposition of lipoprotein debris on the arterial surface or in an indirect manner with predominance of lipoproteins such as chylomicrons, VLDL and LDL-c. ${ }^{18}$

Postprandial lipemia is characterized by a state of hypertriglyceridemic transition and reflects an integrated measure of individual ability to remove TAG, the fasting concentrations of which, in turn, have been shown to be related to the size of LDL-c particles. This response can be subject to increased fatty acid mobilization, synthesis of VLDL-c and delays in its removal, providing greater interaction between lipoproteins and contributing to the formation of small dense particles of LDL-c, which are highly atherogenic. Therefore, interventions to attenuate postprandial lipid response can be considered beneficial to cardiovascular health. ${ }^{5,10}$

\section{TRAINING AND PROGRESSION OF ATHEROSCLEROTIC PLAQUES}

Atherosclerosis is a multifactorial inflammatory disease arising from endothelial injury, mainly acting on the intimal layer of arteries with medium and large calibers. ${ }^{19,20}$ Atherosclerotic plaque formation begins with vascular wall aggression that occurs due to various risk factors such as high plasma lipoprotein levels (LDL, IDL, VLDL and chylomicron remnants), systemic arterial hypertension, dyslipidemia, obesity and smoking. After hydrolysis, chylomicron remnants may become atherogenic, especially if they penetrate to the arterial tissue. ${ }^{21}$

Atherosclerosis is also characterized by the arterial wall thickening that is seen as an accumulation of fat and collagen fibers. Atherogenesis and thickened growth occurs gradually through a process that involves endothelial injury, ${ }^{4}$ tissue proliferation, infiltration and accumulation of lipids derived from plasma and tissue necrosis. Macrophages are intense inflammatory cells with lipid metabolism and are determinants of the development of atherosclerosis because they accumulate large quantities of cholesterol inside themselves. ${ }^{22}$ They have scavenger receptors that are specific for oxidized LDL (oxLDL), which is strongly associated with increased PL in coronary disease because of secretion of inflammatory mediators harmful to the endothelium. Lipid accumulations also stimulate these cells' secretory and proliferative capacity to increase, in a positive feedback process. Changes in lipid profile promote increased vascular stress, activating transcription factors essential for many intracellular signals of inflammatory response that are responsible, among other things, for inducing expression of adhesion molecules (ICAM, VCAM) and consequent 
increased infiltration of the endothelial layer by macrophages. ${ }^{2}$

Adhesion molecules and classic inflammatory markers are observed after high-fat food intake. Gill and Hardman ${ }^{5}$ reported a strong relationship between elevated fast plasma TAG and high levels of interleukin-6 (IL-6) and tumor necrosis factor alpha (TNF- $\alpha$ ) in untrained subjects, but did not attempt to relate their results to endothelial dysfunction. ${ }^{5}$

Early stages of endothelial lesions and of atherosclerotic plaque formation can be observed even in later fetal development. ${ }^{19}$ Abnormal levels of TC, TAG, HDL-c, LDL-c and Lp (a) are also directly associated with genesis and progression of atherosclerosis. ${ }^{1}$ Scientific evidence shows that for a given reduction of LDL-c there is a proportional reduction in the risk of coronary events, which were not associated with lipid values or absolute baseline risk. ${ }^{2}$ This means that the absolute benefit of the intervention is directly related to the initial absolute risk of occurrence of events arising from CVD, such as sudden death and myocardial infarction itself. ${ }^{23}$ Over the last three decades, the hypothesis about the effect lipoproteins have in patients with CVD has been confirmed, showing that decreases in LDL-c plasma levels induced by exercise and increased lipoprotein lipase activity lead to reductions in mortality in patients at high risk of developing CVD. ${ }^{9,13,23,24}$

\section{EFFECTS OF PHYSICAL EXERCISE ON LIPOPROTEIN LIPASE ACTIVITY}

Physical activity, both aerobic and strength training or a mixture of the two, in combination with a controlled diet can effectively prevent and improve obesity, hyperlipidemia and CVD, due to its effect in increasing lipoprotein lipase (LPL) enzyme activity. ${ }^{24}$ The LPL enzyme is found in the capillaries of adipose tissue, the heart and skeletal muscle. It is known to aid in the removal of blood chylomicrons and in catalyzing TAG to free fatty acids and glycerol. Lipoprotein lipase may also have an anchoring function, attaching chylomicron remnants to the liver wall, where the re-esterification process occurs. ${ }^{25} \mathrm{In}$ adipose tissues and skeletal muscle, LPL activity is regulated in a dependent manner (i.e. increased LPL activity in one type of tissue is closely associated with a decrease in the LPL activity of the other). Insulin release attenuates the LPL activity of skeletal muscle, but potentiates its activity in adipose tissues, which is important during fasting periods. ${ }^{11,24}$ The activity of LPL is elevated by exercise, especially in the recovery period after one bout of strength exercise.

\section{EFFECTS OF STRENGTH TRAINING ON POSTPRANDIAL LIPEMIA}

Aerobic exercise performed between 15 and 18 hours prior to ingestion of a high fat meal may attenuate PL response. ${ }^{5}$ The energy expended during aerobic exercise is an important factor in inducing PL reduction. ${ }^{7}$ Few studies have evaluated the influence of strength exercises on PL. ${ }^{9,11,24,26,27}$ Notwithstanding, strength exercise is widely recommended by health associations to improve quality of life and weight management and for prevention of several diseases. ${ }^{20}$

To our knowledge, only five studies ${ }^{9,11,24,26,27}$ have analyzed the influence of the main strength training variables such as volume (number of sets) on PL. Furthermore, these studies contradict each other, and when comparing different volumes only one study ${ }^{24}$ reported an acute reduction in PL concentrations. In contrast, three studies ${ }^{11,26,27}$ failed to observe any reduction in PL after a single session of strength exercises.

Only one study ${ }^{11}$ examined the dose-response characteristics of three different volumes of strength exercises on PL (one, three and five sets of ten maximum repetitions, plus a control group that did not exercise), finding no significant difference between doses. However, experimental subjects consumed more energy and fat than the control group the night before the fat tolerance test. This may have increased the possibility that modifying the diet was a confounding factor masking the effect of strength training on glycemic response. It would therefore be interesting to examine the effect of different doses of strength training on PL without suppressing exercise-related events, including energy deficit and physiological, metabolic and hormonal disturbances. Moreover, the authors of that study ${ }^{11}$ based their results on a mixed sample of men and women, but reported different PL responses between the sexes.

Singhal et al. ${ }^{9}$ have evaluated the effect of different intensities of strength exercises in PL using moderate (60-65\% of 1RM, p=0.052) and high intensities (85-90\% of 1RM, p=0.014). Indeed, it seems that multiple series at moderate intensity, ${ }^{9}$ when compared with multiple series ${ }^{21}$ at high intensity, ${ }^{9}$ substantially reduce the total time and muscular recovery period followed by lower plasma concentrations of CRP, TNF- $\alpha$ and IL- $6 .{ }^{25}$

Notwithstanding, several studies indicate that multiple sets are superior to single series of exercise in terms of neuromuscular and morphological adaptations, although little is known about the metabolic and biochemical changes that occur in 
response to different volumes and intensities of strength training. ${ }^{9}$

In view of the contradictory results described above, the effects of strength training on PL requires further investigation. We did not find any studies that have investigated the effects of different volumes before and after strength training. Zafeiridis et al. ${ }^{21}$ investigated the effects of strength training on TAG response in the postprandial period and observed a reduction in PL with a six-hour protocol and a reduction in the total area under the TAG curve after conducting a session of strength training. The protocol included an energy intake of 0.76 or $1.40 \mathrm{MJ}$ depending on exercise intensity. The same author recently completed a study that evaluated the effects of an aerobic exercise protocol and a strength exercise protocol in which they evaluated total estimated energy expenditure at 5.1 $\mathrm{MJ}$ and observed decreases of $12 \%$ and $18 \%$ respectively on the total elementary AUC of plasma PL. The evidence on this topic is still confused, since there is one study that disagrees with these results. Petitt et al. ${ }^{24}$ observed a reduction in PL concentrations after a single session of strength exercises, with energy expenditure estimated at 1.7 MJ. The main results of the aforementioned studies are presented in Table 2.

\section{STRENGTH TRAINING CARDIOVASCULAR DISEASE (CVD)}

AND

Strength training is known to be a strong inducer of changes in neuromuscular, morphological and metabolic conditions. Adaptations found during this period of strength training have been associated with a protective effect including reduced mortality and incidence of metabolic syndrome. ${ }^{24}$ Evidence from epidemiological studies shows that there is a relationship between reduced risk of coronary heart diseases and regular participation in strength training. ${ }^{18,21}$

Paffenbarger and $\mathrm{Hale}^{28}$ investigated the effects of occupational activity on the development of CVD in dockers. Dockworkers who performed hard physical labor, such as lifting and loading of heavy loads, had a lower mortality rate for coronary heart disease when compared to dockers who did not perform strenuous physical tasks. In another study about the effect of strength training on cardiovascular responses, Tanasescu et al. ${ }^{29}$ found that individuals who performed 30 minutes of strength exercises per week were at $23 \%$ lower risk of developing coronary heart disease than individuals who did not perform any weight training. However, the benefits of strength exercise on risk factors for development of cardiac diseases are not well established.

Cardiovascular diseases share a common pathophysiology involving atherosclerosis and thrombosis. ${ }^{9,29}$ Disorders of lipoprotein metabolism during the postprandial period can promote atherosclerosis due to accumulation of LDL-c and VLDL remnants in plasma after catabolism of these lipoproteins, which increases susceptibility to oxidation of these particles. ${ }^{13}$

Atherosclerosis is a disease that is not only characterized by lipid accumulation, but also by a chronic inflammatory process. ${ }^{27} \mathrm{C}$-reactive protein (CRP) is a classic marker of the inflammatory process associated with atherosclerosis that can also play an etiologic role in atherogenesis. Epidemiological research by Paffenbarger and Hale, ${ }^{28}$ suggests that strength work is beneficial to health, and it is possible that the energy expenditure incurred in this effort provides some cardioprotective effects. It therefore remains important to determine how much strength exercise is beneficial to cardiovascular health, mainly for specific populations.

Table 2. Methods and results of studies reporting the effects of strength exercise on $\mathrm{PL}$ (adapted from Zafeiridis et al. ${ }^{21}$ ).

\begin{tabular}{|c|c|c|c|c|c|c|}
\hline Reference & MR & Series & $\begin{array}{c}\text { Interval } \\
(\mathrm{min})\end{array}$ & $\begin{array}{l}\text { Total time of SEB } \\
(\min )\end{array}$ & $\begin{array}{c}\text { Total EE } \\
\text { (kcal/min and total) }\end{array}$ & $\begin{array}{c}\downarrow \text { PL-TAG in AUC relative } \\
\text { to control (\%) }\end{array}$ \\
\hline Petitt et al. ${ }^{6}$ & 10 & 3 & 2 & 88 & $4.62(406.6)$ & $14(p=0.05)$ \\
\hline \multirow[t]{3}{*}{ Shannon et al. ${ }^{11}$} & 10 & 1 & 1 & 20 & $6.85(137.0)$ & NS \\
\hline & 10 & 3 & 1 & 48 & $6.85(328.8)$ & NS \\
\hline & 10 & 5 & 1 & 90 & $6.85(616.5)$ & NS \\
\hline Burns et al. ${ }^{27}$ & 10 & 4 & 2 & 88 & $6.25(550.0)$ & NS \\
\hline \multirow[t]{2}{*}{ Zafeiridis et al. ${ }^{21}$} & 12 & 2 & 1.5 & 39 & 4.66 (181.7) & $20(p=0.017)$ \\
\hline & 12 & 4 & 1.5 & 79 & $4.24(335.0)$ & $24(p=0.004)$ \\
\hline \multirow[t]{2}{*}{ Singhal et al. ${ }^{9}$} & 8 & 3 & 3 & 90 & $4.18(376.2)$ & $26(p=0.052 ; N S)$ \\
\hline & 16 & 3 & 2.3 & 90 & $4.81(432.9)$ & $35(p=0.014)$ \\
\hline
\end{tabular}

MR, maximum repetition; SEB, strength exercise bout; EE, energy expenditure; PL, postprandial lipemia; TG, triglycerides; AUC, area under curve; NS, not significant. 


\section{CONCLUSIONS}

This review supports the hypothesis that resistance exercise has a direct relationship with changes in postprandial lipemia that are associated with cardiovascular disease. However, few studies have looked at the effects of this intervention on changes in the lipid profile after fasting or after a high-fat meal. Strength training proved more effective than aerobic exercise for reducing PL concentrations by increasing resting energy expenditure without necessarily correlating with changes in body composition. Indeed, strength training appears to be a crucial tool for improving lipid parameters through greater efficiency of energy demand, and can therefore be considered an important non-pharmacological strategy for reducing risk factors for development of CVD.

\section{REFERENCES}

1. Zilversmit DB. Atherogenesis: a postprandial phenomenon. Circulation. 1979;60(3):473-85. PMid:222498 http://dx.doi. org/10.1161/01.CIR.60.3.473

2. Zilversmit DB. Atherogenic nature of triglycerides, postprandial lipidemia, and triglyceride-rich remnant lipoproteins. Clin. Chem. 1995;41(1):153-8.

3. Zaman GS, Rahman S, Rahman J. Postprandial lipemia in preand postmenopausal women. J Nat Sci Biol Med. 2012;3(1):6570. PMid:22690054 PMCid:PMC3361781 http://dx.doi. org/10.4103/0976-9668.95961

4. Quagliaro L, Piconi L, Assaloni R, et al. Intermittent high glucose enhances ICAM-1, VCAM-1 and E-selectin expression in human umbilical vein endothelial cells in culture: the distinct role of protein kinase $\mathrm{C}$ and mitochondrial superoxide production. Atherosclerosis. 2005;183(2):259-67. PMid:16285992 http:// dx.doi.org/10.1016/j.atherosclerosis.2005.03.015

5. Gill JM, Hardman AE. Postprandial lipemia: effects of exercise and restriction of energy intake compared. Am J Clin Nutr. 2000;71(2):465-71. PMid:10648259

6. Petitt DS, Cureton KJ. Effects of prior exercise on postprandial lipemia: a quantitative review. Metabolism. 2003;52(4):418-24. PMid:12701052 http://dx.doi.org/10.1053/meta.2003.50071

7. Tsetsonis NV, Hardman AE. Reduction in postprandial lipemia after walking: influence of exercise intensity. Med Sci Sports Exerc. 1996;28(10):1235-42. http://dx.doi. org/10.1097/00005768-199610000-00005

8. Libardi CA, Souza GV, Gaspari AF, et al. Effects of concurrent training on interleukin-6, tumour necrosis factor-alpha and C-reactive protein in middle-aged men. J Sports Sci. 2011;29(14):1573-81. PMid:21933039 http://dx.doi.org/10.1080/02640414.2011.609896

9. Singhal A, Trilk JL, Jenkins NT, Bigelman KA, Cureton KJ. Effect of intensity of resistance exercise on postprandial lipemia. J Appl Physiol. 2009;106(3):823-9. PMid:19150861 http://dx.doi. org/10.1152/japplphysiol.90726.2008

10. Parks EJ. Recent findings in the study of postprandial lipemia. Curr Atheroscler Rep. 2001;3(6):462-70. PMid:11602066 http://dx.doi. org/10.1007/s11883-001-0036-5

11. Shannon KA, Shannon RM, Clore JN, Gennings C, Warren BJ, Potteiger JA. Resistance exercise and postprandial lipemia: the dose effect of differing volumes of acute resistance exercise bouts. Metabolism. 2005;54(6):756-63. PMid:15931610 http://dx.doi. org/10.1016/j.metabol.2005.01.017

12. Durstine JL, Grandjean PW, Cox CA, Thompson PD. Lipids, lipoproteins, and exercise. J Cardiopulm Rehabil Prev. 2002;22(6):385-98. http://dx.doi. org/10.1097/00008483-200211000-00002

13. Kolovou GD, Mikhailidis DP, Bilianou H, Panotopoulos G, Nordestgaard BG. Definition of Postprandial Lipaemia. Curr Vasc Pharmacol. 2011;9(3):292-301. PMid:21314628 http://dx.doi. org/10.2174/157016111795495611

14. Henry NG. Nonpharmacologic management of low levels of highdensity lipoprotein cholesterol. The Am J Cardiol. 2000;86(12):41-5. http://dx.doi.org/10.1016/S0002-9149(00)01469-7

15. Pearson TA, Blair SN, Daniels SR, et al. AHA guidelines for primary prevention of cardiovascular disease and stroke: 2002 Update. Consensus panel guide to comprehensive risk reduction for adult patients without coronary or other atherosclerotic vascular diseases. Circulation. 2002;106(3):388-91. PMid:12119259 http:// dx.doi.org/10.1161/01.CIR.0000020190.45892.75

16. Blankenberg S, Barbaux S, Tiret L. Adhesion molecules and atherosclerosis. Atherosclerosis. 2003; 170(2):191-203. http:// dx.doi.org/10.1016/S0021-9150(03)00097-2

17. Patsch JR, Miesenbock G, Hopferwieser T, et al. Relation of triglyceride metabolism and coronary artery disease: studies in the postprandial state. Arterioscler Thromb. 1992;12(11):133645. PMid:1420093 http://dx.doi.org/10.1161/01.ATV.12.11.1336

18. Wooten JS, Phillips MD, Mitchell JB, et al. Resistance exercise and lipoproteins in postmenopausal women. Int J Sports Med. 2011;32(1):7-13. PMid:21086242 PMCid:PMC3354704 http://dx.doi.org/10.1055/s-0030-1268008

19. Napoli C, D'Armiento FP, Mancini FP, et al. Fatty streak formation occurs in human fetal aortas and is greatly enhanced by maternal hypercholesterolemia: intimal accumulation of low density lipoprotein and its oxidation precede monocyte recruitment into early atherosclerotic lesions. J Clin Invest. 1997;100(11):2680-90. PMid:9389731 PMCid:PMC508471 http://dx.doi.org/10.1172/ $\mathrm{JCl} 119813$

20. Pafili ZK, Bogdanis GC, Tsetsonis NV, Maridaki M. Postprandial lipemia 16 and 40 hours after low-volume eccentric resistance exercise. Med Sci Sports Exerc. 2009;41(2):375-82. PMid:19127187 http://dx.doi.org/10.1249/MSS.0b013e31818703ec

21. Zafeiridis A, Goloi E, Petridou A, Dipla K, Mougios V, Kellis $S$. Effects of low- and high-volume resistance exercise on postprandial lipaemia. Br J Nutr. 2007;97(3):471-7. PMid:17313708 http://dx.doi.org/10.1017/S0007114507336787

22. Goumas G, Tentolouris C, Tousoulis D, Stefanadis C, Toutouzas $P$. Therapeutic modification of the L-arginine-eNOS pathway in cardiovascular diseases. Atherosclerosis. 2001;154(2):255-67. http://dx.doi.org/10.1016/S0021-9150(00)00736-X

23. Tsetsonis NV, Hardman AE, Mastana SS. Acute effects of exercise on postprandial lipemia: a comparative study in trained and untrained middle-aged women. Am J Clin Nutr. 1997;65(2):52533. PMid: 9022540

24. Petitt DS, Arngrimsson SA, Cureton KJ. Effect of resistance exercise on postprandial lipemia. J Appl Physiol. 2003;94(2):694-700. PMid:12391139

25. LeMura LM, Von Duvillard SP, Andreacci J, Klebez JM, Chelland SA, Russo J. Lipid and lipoprotein profiles, cardiovascular fitness, body composition, and diet during and after resistance, aerobic and combination training in young women. Eur J Appl 
Physiol. 2000;82(5-6):451-8. PMid:10985600 http://dx.doi. org/10.1007/s004210000234

26. Burns SF, Corrie H, Holder E, Nightingale T, Stensel DJ. A single session of resistance exercise does not reduce postprandial lipaemia. J Sports Sci. 2005;23(3):251-60. PMid:15966343 http:// dx.doi.org/10.1080/02640410410001730142

27. Burns SF, Stensel DJ. Effects of low- and high-volume resistance exercise on postprandial lipaemia. Br J Nutr. 2008;99(1):211. PMid:18086333 http://dx.doi.org/10.1017/S0007114507761755

28. Paffenbarger RS, Hale WE. Work activity and coronary heart mortality. N Engl J Med. 1975;292(11):545-50. PMid:1128551 http://dx.doi.org/10.1056/NEJM197503132921101

29. Tanasescu M, Leitzmann MF, Rimm EB, Willett WC, Stampfer MJ, $\mathrm{Hu} F \mathrm{~F}$. Exercise type and intensity in relation to coronary heart disease in men. JAMA. 2002;288(16):1994-2000. PMid:12387651 http://dx.doi.org/10.1001/jama.288.16.1994
Correspondence

Cleiton Silva Correa

Universidade Federal do Rio Grande do Sul - UFRGS, Exercise Research Laboratory - LAPEX Rua Felizardo, 750 - Jardim Botânico CEP 90690-200 - Porto Alegre (RS), Brazi Tel.: +55 (51) 3308-5862 E-mail: cleitonesef@yahoo.com.br

Author information

CSC é Doutor pela Universidade Federal do Rio Grande do Sul (UFRGS) e Coordenador do Curso de Educação Física da Universidade Regional Integrada do Alto Uruguai e das Missões (URI) da cidade de São Luiz Gonzaga.

BCT é Mestre pela Universidade Federal do Rio Grande do Sul (UFRGS)

AB é Bacharel em Educação Física pela Universidade Federal do Rio Grande do Sul (UFRGS)

RCOM é Mestre pela Universidade Federal do Rio Grande do Sul (UFRGS)

ARO é Professor Titular pela Universidade Federal do Rio Grande do Sul (UFRGS)

Author contributions Conception and design: CSC, BCT, AB, RCOM, ARO Analysis and interpretation: CSC, BCT, RCOM, ARO Data collection: CSC, BCT Writing the article: CSC, BCT, $A B, A R O$ Critical revision of the article: CSC, $B C T, A B, R C O M, A R O$ Final approval of the article*: CSC, BCT, AB, RCOM, ARO Statistical analysis: N/A Overall responsibility: CSC, ARO

* All authors have read and approved of the final version of the article submitted to J Vasc Bras. 